\title{
Configuraciones del Tiempo en el Mar Interior de Chiloé y su relación con la apropiación de los Territorios Marítimos*
}

\section{Configurações do tempo no Mar Interior de Chiloé e sua relação com a apropriação dos territórios marítimos}

\section{Configurations of Time in the Interior Sea of Chiloé and its Relation with the Appropriation of Maritime Territories}

\author{
Francisco THER Ríos**
}

\begin{abstract}
RESUMEN
Este trabajo es una aproximación antropológica al territorio y la construcción social del tiempo en el Mar Interior de Chiloé, Chile. Se trata de un territorio de mar y borde mar cargado de puertos y lugares de llegada, en el cual confluyen distintos trayectos marítimos entre islas y sectores poblados que estructuran trayectorias y dinámicas plasmadas en memorias del pasado e imaginarios del futuro. El maritorio chilote, en tanto sistema territorial y patrimonial en el que han confluido diversas relaciones entre factores pragmáticos, posibilita la reproducción de trayectorias de economías y simbolismos costeros, lo cual en su conjunto inscribe y proyecta distintas configuraciones del tiempo. Se sostiene como hipótesis que los continuos procesos de presentificación del pasado en el mar interior de Chiloé contemporáneo, expresados en memorias costeras de pescadores artesanales, y los procesos de futurización del pasado manifestados en imaginarios territoriales, revelan las formas en que se construye socialmente el tiempo en este maritorio. Para esto conjeturamos, que las memorias costeras, al explorar el pasado de rutas y trayectorias, realizan un verdadero viaje retrospectivo; de este modo, la experiencia ganada a través de las rutas y trayectorias a lo largo del tiempo implica que los pescadores desarrollen cotidianamente estrategias que, apoyadas en la memoria y la fortaleza que ella les otorga, permiten adaptarse a los procesos de modernización.
\end{abstract}

Palabras clave: Mar Interior de Chiloé; territorios marítimos; pesca artesanal; memoria e imaginario.

\section{RESUMO}

Este trabalho é uma aproximação antropológica do território e a construção social do tempo no Mar Interior de Chiloé, Chile. Trata-se de um território de mar e litoral carregado de portos e lugares de che-

\footnotetext{
"Este trabajo es resultado del Proyecto FONDECYT 1080665 "Las sociedades litorales como sistemas de prácticas y saberes tradicionales y científicos: la caleta como modelo de imaginarios pesqueros y dinámicas de uso y apropiación de recursos marinos".

"* Antropólogo Social. Investigador do Centro de Estudios del Desarrollo Local y Regional / Universidad de Los Lagos, Chile. Email: fther@ulagos.cl.
} 
gada, para o qual confluem diferentes trajetos marítimos entre ilhas e setores povoados que estruturam trajetórias e dinâmicas fixadas em memórias do passado e imaginários do futuro. $\mathrm{O}$ espaço territorial marítimo de Chiloé, como sistema territorial e patrimonial para o qual confluem diversas relações de fatores pragmáticos, possibilita a reprodução de trajetórias de economias e simbolismos costeiros, que em seu conjunto inscrevem e projetam diferentes configurações de tempo. Sustentamos a hipótese de que os continuados processos de presentificação do passado no mar interior de Chiloé contemporâneo, traduzidos em memórias costeiras de pescadores artesanais, com os processos de futurização do passado manifestados nos imaginários territoriais, revelam as formas pelas quais se constrói socialmente o tempo neste espaço. Para isto, presumimos que as memórias costeiras, ao explorar o passado de rotas e trajetórias, realizam uma verdadeira viagem retrospectiva; assim, a experiência ganha através de rotas e trajetórias ao longo do tempo implica que os pescadores desenvolvem cotidianamente estratégias que, apoiadas na memória e na fortaleza proporcionada pela experiência, permitem adaptar-se aos processos de modernização.

Palavras-chave: Mar Interior de Chiloé; territórios marítimos; pesca artesanal; memória e imaginário.

\begin{abstract}
This work is an anthropologic approach to the territory and the social construction of time in the Interior Sea of Chiloé, Chile. It is a maritime and coastal territory filled with ports and places of arrival, in which different maritime routes find confluence among islands and populated sectors that structure paths and dynamics fixed in memories of the past and imageries of the future. The maritime territory space of Chiloé, while territorial and patrimonial system in which diverse relations have come together among pragmatic factors, makes the reproduction of paths of economies and coastal symbolisms possible, which in its set inscribes and projects different configurations of the time. We support the hypothesis that the continuous processes of "presentification" of the past in the interior sea of contemporary Chiloé, expressed in coastal memories of handcrafted fishermen, and the processes of "futurization" of the past, demonstrated in territorial imaginary, reveal the forms in which the time is constructed socially in this space. For this we surmise that the coastal memories, on having explored the past of routes and paths, realize a real retrospective trip; thus, the experience gained across the routes and paths along the time implies that the fishermen develop daily strategies that, supported on the memory and the strength of their experience, allow them to adapt to the processes of modernization.
\end{abstract}

Key-words: Mar Interior de Chiloé; maritime territories; handcrafted fishing; memory and imaginary.

\section{Introducción: la relevancia del estudio de las configuraciones del tiempo en el Mar Interior de Chiloé}

El Mar Interior de Chiloé es un territorio de mar y borde mar cargado de puertos y lugares de llegada, en el cual confluyen distintos trayectos marítimos entre islas y sectores poblados que estructuran trayectorias y dinámicas plasmadas en memorias del pasado e imaginarios del futuro. El maritorio chilote, en tanto sistema territorial y patrimonial en el que han confluido diversas relaciones entre factores pragmáticos (económicos, tecnológicos, productivos) y cognoscitivos (distintas racionalidades que han entrado en juego), ha sido y es la physis que posibilita la reproducción de trayectorias de economías y simbolismos costeros, lo cual en su conjunto inscribe y proyecta distintas configuraciones del tiempo.

En este sentido, interesa comentar cuestiones fundamentales situadas en nuestro conocimiento sobre las trayectorias y dinámicas en el maritorio chilote, y que implica el punto nodal desde donde inferimos lo significativo de las apropiaciones socioculturales del mar (cf. VIEIRA; WEBER, 1997), tanto en su relativa permanencia, como en sus procesos de cambio.

Estimamos que en el sistema patrimonial manifestado bajo el término de maritorio chilote se han metaforizado y generado afectos y memorializaciones que son, a nuestro 
juicio, los caracteres más relevantes de este sistema territorial. Se estima que el conocimiento y valoración del maritorio chilote es fuente significativa para la comprensión de Chiloé, para su condición metafísica e histórica, así como también para sus proyecciones. Lo que, por retroefecto, da a la cultura chilota un impulso en su contribución al desarrollo, principalmente, por lo multifacético con que el maritorio se presenta ante los requerimientos humanos y lo profundamente arraigado que está en relación a sus prácticas y representaciones simbólicas, cultos y rituales, tanto de la diversidad como de la identidad social.

El maritorio de Chiloé - esto es, el mar, las apropiaciones socioculturales y actores-, configura un entramado complejo (THER, 2006; VIEIRA; WEBER, 1997) que no se da simplemente, sino que se va construyendo, espacial y temporal en un marco de significatividades localizadas en rutas y trayectorias. Parafraseando a Arizpe (2006) el maritorio chilote proporciona entonces servicios culturales y económicos. Desde el punto de vista del desarrollo territorial, debate y reflexión sobre este sistema territorial y patrimonial es pertinente para instalar sentidos patrimoniales para el presente y futuros posibles de Chiloé. La patrimonialización es un proceso fundamental, social y cultural, que estaría en la base de todo desarrollo (BUSTOS CARA, 2004). Apoyados en Castoriadis (1984) consideramos que el desarrollo del maritorio chilote implica tanto un potencial que ya está ahí como una realización con determinaciones no explicitadas que requieren dejarse ver; la evidenciación del maritorio - en tanto sistema territorial y patrimonial - implica fundar, pensar y prospectar el desarrollo del Mar Interior de Chiloé en los patrimonios costeros de rutas y trayectorias, lo cual supone los diversos pasados de las colectividades humanas, como también las contemporaneidades y proyecciones futuras de este maritorio. En este encuadre, se estima que las rutas y trayectorias en el mar chilote han trascendido las cuestiones puramente económicas o turísticas y folklóricas, para ser cuestiones claves de desarrollo. Pero el desarrollo, en tanto que no es espontáneo o natural, refiere a procesos motivados. La fuerte relación emotiva que rodea a las rutas y trayectorias marítimas en Chiloé, y el deseo de despertar en ellas y en torno a ellas la memoria colectiva, conduce a generar afectos que transforman las cosas, de meros objetos de algún tipo, técnicos, pragmáticos, artísticos, culturales, naturales, etc., en sistemas patrimoniales. Este es el punto en que la cultura chilota se juega su mejor posibilidad para construir o frenar el desarrollo, para valorar el cambio o cultivar la permanencia. De esta manera el maritorio chilote puede ser considerado como fuente de procesos y recursos, y no solamente como objeto de preservación, haciendo que la memoria sea funcional al futuro (en un sentido positivo), y que la sociedad se reconozca en sus memorias.

\section{Rutas y trayectorias en el Mar Interior de Chiloé: Áreas Geoculturales Marítimas}

Los procesos de apropiación del Mar Interior de Chiloé, permite agrupar diversas investigaciones y estudios en 6 momentos históricos ${ }^{1}$, cada uno señalando distintas rutas y trayectorias, describiendo así mismo motivos cotidianos diversos de los usuarios, sus sueños y anhelos. En conjunto, los estudios de diversos investigadores se constituyen en información relevante para reconstruir los juegos de memorias e imaginarios que han impregnado tradiciones en el Mar Interior de Chiloé a lo largo de los tiempos.

\section{Momento 1: Memorias e imaginarios de la Prehistoria en el Mar Interior de Chiloé}

Varios autores destacan la utilización de canoas durante la prehistoria en el mar interior de Chiloé (CÁRDENAS et al., 1993; DILLEHAY, 2004; LIRA, 2007, BRAICOVICH; CARACOTCHE, 2008; BELLELLI et al., 2008). Una imagen representada por Alonso de Ercilla (1558) muestra las aguas del seno de reloncaví y las islas aledañas habitadas por embarcaciones que se movían de un lugar a otro, se trata de trayectorias recorridas cotidianamente por algunos grupos indígenas:
De Ancud el espacioso y fértil raso,
Y al pie del monte y áspera ladera
Un extendido lago y gran ribera
Era un ancho archipiélago poblado
De innumerables islas deleitosas,
Cruzando por uno y otro lado
Góndolas y piraguas presurosas

(Alonso de Ercilla, Extracto de La Araucana)

\footnotetext{
${ }^{1}$ En esta sistematización ha sido fundamental el aporte del antropólogo Claudio Gajardo C. del Centro de Estudios del Desarrollo Local y Regional de la Universidad de Los Lagos.
} 
Durante este periodo existieron contactos entre grupos canoeros en el norte de la isla de Chiloé (RAMÍREZ, 1997; MANSILLA, 2002, 2005). La denominada isla Lagartija, perteneciente al archipiélago de Calbuco "fue por siglos un lugar de canoeros y recolectores que deambulaban por las costas del golfo de Ancud y el Reloncaví donde junto con sus islas aledañas, "confluían los veliche, junco, chono y hasta poya cordilleranos" (MANSILLA, 2002, p. 126). Por otra parte las estrategias de búsqueda de alimentos con complementariedad de nichos ecológicos (GUEVARA, 1925; OYARZUN, 1934; ZAPATER, 1973; DILLEHAY, 1990 en TORREJÓN, 2004; GAETE; NAVARRO, 2004; FLORES, 2007) señalan la primera de las rutas que consistió en la utilización por parte de los Chono del mar interior de Chiloé como un corredor que les permitía ir desde el archipiélago que lleva su nombre (XI Región de Aysén) y actual Zona Contigua $^{2}$ para luego arribar al Seno de Reloncaví ${ }^{3}$ en busca de alimentación y exploración propia de su vida nómade. También existía una firme adaptación en ambientes costeros y marítimos por parte de grupos indígenas (LEGOUPIL; FONTUGNE, 1997; ORQUERA; PIANA, 1999; RIVAS et al., 1999; OCAMPO; RIVAS, 2004; GAETE et al., 2004; MARTINIC, 2005). En las rutas y circuitos que conectan islas y riberas del mar interior (CÁRDENAS et al., 1993; ÁLVAREZ; GODOY, 2001; ÁLVAREZ, 2002, 2004; TRIVERO, 2005; ÁLVAREZ et al., 2008), aparecen dos trayectos: una que cubre las islas y alrededores lacustres del seno de Reloncaví y el Golfo de Ancud (GAETE et al., 2004; CHAPANOFF, 2009); y otra que conecta el archipiélago de los Chonos y las islas Guaitecas con el sector del mar interior y sur de la isla de Chiloé (MENA, 1985; PORTER, 1992; LEGOUPIL, 2005; ASPILLAGA et al., 2006; HUCKE-GAETE et al., 2008, 2009). Esta última ruta muestra que la zona que comprende el mar interior desde el norte de Chiloé hasta la región de Aysén se constituye tempranamente por "la existencia de sistemas marítimos, desde la isla de Chiloé hasta zonas australes... como una zona de tránsito entre pueblos vecinos. Existiendo de esta manera, un modo particular y común de habitar y usar los espacios marítimos" (HUCKE-GAETE et al., 2008, p. 22).

\section{Momento 2: Memorias e imaginarios del Siglo XVI en el Mar Interior de Chiloé}

Durante este periodo la principal motivación para utilizar el mar interior de Chiloé fue el deseo de explorar y conquistar el Estrecho de Magallanes (VÁZQUEZ DE ACUÑA, 1988), conociéndose 2 rutas utilizadas: a) una externa al mar interior (MANSILLA, 1992) y una interna a él (THAYER OJEDA, 1913). La primera de estas rutas bordeba la costa occidental de la Isla de Chiloé dirigiéndose a Magallanes, a través de la cual los exploradores visitaban el canal de Chacao y la Isla Guafo (FERRER, 1988; BARROS ARANA, 2000). En la práctica las naves de colonización, exploración y comercialización, siguieron durante este periodo el mapa construido por el imaginario indígena de las rutas definidas a través de prácticas ancestrales en función de saberes sobre configuraciones ambientales de corrientes $\mathrm{y}$ vientos que abren cierran pasos.

Una de las primeras expediciones fue la de Francisco de Ulloa en 1553, que por encargo de Pedro de Valdivia, salió en busca de una ruta hacia el Estrecho de Magallanes. Francisco de Ulloa viajó desde la ciudad de Valdivia y navegó por el borde occidental de la Isla de Chiloé para la luego introducirse y explorar el golfo que separa la Isla del continente, denominándolo Golfo de los Coronados, el cual se conecta con el Canal del Chacao, se conecta con el golfo de Ancud que es la entrada norte al mar interior de Chiloé ${ }^{4}$.

En la mitología mapuche, apropiada posteriormente por la cultura chilota (MANSILLA, 2008), éste como muchos otros accidentes geográficos (canales, fiordos, islas y formaciones tierra-mar de la zona austral) nacen de la originaria lucha entre la serpiente marina diosa de las aguas (asociada al mal), llamada Cai-cai Vilú (del mapudungun; co: Agua, Vilu: Culebra), cuyas huellas dejadas por su zigzagueante movimiento fue inundando la superficie terrestre, y la serpiente terrestre llamada Tren tren Vilú (asociada al bien) que con su movimiento eleva la tierra en forma de cerros y colinas para salvar a los hombres de convertirse en lobos o

\footnotetext{
${ }^{2}$ Zona limítrofe entre la Región de los Lagos y la Región de Aysén. Producto de que los pescadores no respectan este límite regional en sus jornadas de pesca, continuando con la tradición histórica de no tener un límite regional. Se ha instalado una mesa de trabajo público-privada pero resulta ser una operación redundante. ${ }^{3}$ Los Chono vivieron hasta fines del siglo XVIII habitando entre el golfo de penas y Chiloé. Poseían un sistema de vida nómade con gran adaptación marítima centrado en la caza de lobo marino y la recolección de mariscos. Por razones aún desconocidas se extinguieron durante la época colonial. "Cuando Darwin visitó, en 1835, la islas Chonos, hacía ya mucho tiempo que no vivía allí ningún indio" (EMPERAIRE, 1963).

${ }^{4}$ El nombre puesto por Francisco de Ulloa al "Golfo de los Coronados", refiere a la historia de cuatro hombres que durante los siglos III y IV bajo el gobierno del Emperador romano Cayo Aurelio Valerio Diocleciano Augusto, se rehusaron a rendir tributo a Esculapio, dios Griego de la medicina y el cálculo, de modo que por ser fieles al cristianismo fueron ejecutados. Posterior a su muerte fueron declarados santos y llamados los cuatro coronados.
} 
peces tras perecer en la inundación (Ibíd.). De allí se forma la accidentada y loca geografia de cruces y disyunciones ${ }^{5}$ entre canales e islas (SUBERCASEAUX, 1940). Desde el punto de vista geomorfológico, el mar interior se debe a un paulatino hundimiento del valle central, de manera que la isla misma es sólo el levantamiento de la Cordillera de la Costa entre los paralelos $41^{\circ} 50$ y $43^{\circ} 20$ Sur. Las pequeñas islas, canales y los fiordos del sector de Chiloé continental, se deben a la erosión causada por el antiguo avance y retroceso de glaciares que prácticamente modeló las curvaturas y fragmentaciones luego cubiertas por el agua (PORTER, 1981).

En 1557 el Gobernador de Chile, García Hurtado de Mendoza inicia la exploración desde Valdivia con una doble finalidad: explorar el Estrecho de Magallanes para encontrar tanto nuevas tierras como indios que encomendar (MANSILLA, 2008). La ruta que realizaron comprendió un largo viaje por tierra donde a su llegada vislumbran el Seno de Reloncaví. Luego bordean el seno y se encuentran en un lugar donde no podían seguir ya que es un enorme desaguadero donde "el mar se topa con la cordillera nevada" (Ibíd.), que es el actual Fiordo de Reloncaví. Desde allí los expedicionarios se embarcan en Dalcas para las islas cercanas de Guar, Tenglo e incluso hacia la Isla de Chiloé. Esta fue la ruta interna, que llegaba por tierra hasta el seno de Reloncaví y desde allí hasta el Canal de Chacao, las Islas de Tenglo, Huar, Maillén (DE CÓRDOBA, 1862) y también parte de la Isla Grande e islas del mar interior (VIDAL GORMAZ, 1870; MANSILLA, 2008).

\section{Momento 3: Memorias e imaginarios del Siglo XVII en el Mar Interior de Chiloé}

En este periodo fueron las misiones jesuitas de evangelización de indígenas de Chiloé el principal motivo para poblar el mar interior de Chiloé (NEGRÓN, 1980; MÜLLER, 2007). Dos fueron las rutas: a) una que iniciando en Castro, se internaba en las islas interiores, seguía por las riberas hasta llegar al Canal de Chacao (MORENO, 2006), específicamente hasta Carelmapu (ANUCH, 2008; HAU, 2006; SANDOVAL, 2007) y desde Carelmapu hacia Nahuelhuapi (ALBORNOZ; HAJDUK, 2001; URBINA, X., 2007; AL-
BORNOZ; MONTERO, 2008); b) otra ruta iba desde Castro hacia las Islas Interiores (URBINA, 1986, 1988, 1990), y desde ahí hacia las islas cercanas a Quellón para desplazarse posteriormente hasta las islas Guaitecas y el archipiélago de los Chonos (GARCÍA, 1889). En estos viajes los indígenas entregaban valiosos datos sobre incursiones militares extranjeras en los canales más meridionales, de manera que con el tiempo, "españoles y mestizos [...] adoptan de los aborígenes las formas de relacionarse con el medio, su modo de moverse por el mar interior" (URBINA, 1988, p. 35). Durante los viajes de la misión circular, la percepción indígena ofrecía ciertas prácticas que el español utilizaba. En general, en los viajes misionales los indígenas realizaban rituales para el buen tiempo, saludaban elementos de la naturaleza, identificaban rutas y alimentos. También cazaban lobos en algunas playas y roqueríos, y recogían huevos de aves en ciertas islas, donde ellos conocían variados recursos naturales comestibles. Al avistar una isla con presencia evidente de pájaros, los indígenas avisaban la detención de la piragua y concurrían nadando hasta esa isla, y encontrando los nidos traían cantidades de huevos en sus manos hacia la piragua la cual después seguía su camino (GARCÍA, 1889).

En 1620 Juan Fernández, y en 1680, Nicolás Mascardi parten desde Calbuco hacia Nahuelhuapi en busca de las míticas ciudades hundidas en la Patagonia. En estos viajes se aprovecharon las potencialidades ecológicas del territorio (GUEVARA, 1925; OYARZUN, 1924; ZAPATER, 1973; DILLEHAY, 1990, en TORREJÓN, 2004), de manera que los colonos asimilaron en la práctica los usos y técnicas de supervivencia utilizadas por los indígenas locales (CONTRERAS et al., 1971; URBINA, 1986). Tanto colonizadores como leñadores buscaban por su cuenta el acceso más cercano a la vía natural de comunicación, "convirtiendo al mar en la vía de relaciones y comunicaciones por excelencia” (SANDOVAL, 2007, p. 10).

\section{Momento 4: Memorias e imaginarios del Siglo XVIII en el Mar Interior de Chiloé}

En este momento, dos fueron los motivos que dieron pie a la utilización del mar interior: la búsqueda de

\footnotetext{
${ }^{5}$ El principio es entonces un diluvio, donde "el mar, la tierra y la montaña aprisionan al hombre como entre dos tenazas, el bien y el mal, disputándose las estrechas tierras" (BENGOA, 2000, p. 15). Por otra parte, la dualidad del bien y el mal entre ambas serpientes, representa el principio del desorden en una situación donde hay desequilibrio sobre quien posee el dominio, lo cual constantemente se ordena y vuelve a desordenar (Memorias del IV Encuentro-Taller Latinoamericano de Teología India, 2004, p. 158).
} 
la mítica Ciudad de los Césares (HANISCH, 1982), y la explotación maderera para abastecer al Virreinato del Perú (SMITH, 1949; CONTRERAS et al,; 1971); en su conjunto esto posibilitó tanto el desarrollo de la ruta de la madera (URBINA, 2007) como de la denominada "cultura de la madera en Chiloé" (VIVALDI; ROJAS, 1992; MARINO; BIANCHI, 1980; MARINO; OSORIO, 1983; MARINO, 1985; SANTANA, 2001, 2004). En este periodo se utilizó la ruta desde Calbuco hacia Nahuelhuapi (URBINA, X., 2007), y otra que consideraba los circuitos entre islas de mares interiores y cercanos a las riberas del Chiloé continental, desde ahí se desplazaban hacia el Virreinato del Perú (RAMÍREZ, 1997).

Según los estudios de Legoupil (2005), la existencia temprana de cazadores-recolectores marítimos en las cercanías de Quellón ligados con los chonos de más al sur, explica "la ayuda eficaz de los indígenas de Chiloé a las expediciones marítimas jesuitas de los Padres Venegas y García, o de Juan Vicuña, en estas zonas alejadas, en el transcurso del siglo XVIII" (LEGOUPIL, 2005, p. 55). Así mismo, "la presencia de pueblos costeros del norte principalmente chilotes - debió ser importante en el sector insular del litoral de Aysén, sobre todo en el archipiélago de Las Guaitecas" (QUIROZ; OLIVARES, 1985; MENA 1985, 1982, citados en HUCKE-GAETE, 2008, p.25) Desde el sur al norte, existió una migración de Indígenas Chono, hacía el fuerte Calbuco en el siglo XVIII, los que fueron radicados en la Isla Guar, asentándose luego en Caylin y Apiao, posteriormente se dispersaron hacia Quiapu, Calbuco, Chaulinec (URBINA, 1988).

$\mathrm{Al}$ igual que en siglos anteriores, quienes guiaron las expediciones en busca de la Ciudad de los Césares fueron "indios chonos, caucahues, poyas y huilliches" (URBINA, 1990, p. 91). Una gran cantidad de viajes se realizaron por el mar interior, con la intención de encontrarla. Las expediciones jesuitas en el siglo XVII partían desde Castro, pasando por el lado del archipiélago de Islas Guaitecas y por el Archipiélago de los Chonos para intentar buscar este mítico lugar (MARTINIC, 2005) .

En definitiva, éste fue el periodo de oro del Chiloé peruano, su producción maderera lo consolidó como una posición privilegiada entre el estrecho interoceánico y Lima. Por primera vez, su comercio Pacífico adquiere ribetes destacables, profundizando, en tanto, el movimiento de hacheros hacia el Chiloé continental (Aysén) que progresivamente van a consolidar los asentamientos costeros.

\section{Momento 5: Memorias e imaginarios del Siglo XIX en el Mar Interior de Chiloé}

En este momento las principales motivaciones para utilizar el mar interior fueron tanto la venta local (VIDAL, 2007) y luego comercialización internacional de la madera nativa (MANSILLA, 2004), como las exploraciones científicas (MANSILLA, 1991). Siendo de gran importancia el viaje de la Goleta Ancud que pasando por el Canal de Chacao, Curaco de Vélez, Archipiélago de las Guaitecas, Archipiélago de los Chonos, llegó luego al Estrecho de Magallanes (RODRÍGUEZ, 2008). En este periodo también se realizan viajes comerciales desde Ancud hasta California y Perú (RODRÍGUEZ, 2008; RAMÍREZ, 1996, 1997); así también fueron importantes las rutas de los exploradores ingleses (Charles Darwin) que navegan desde el Golfo de Ancud hasta el mar interior pasando por Quinchao hacia Lemuy, Cailín e isla San Pedro (MANSILLA, 2005), mientras otro barco inglés exploró las islas Guamblin, Ipun y Guafo (RODRÍGUEZ, 2004).

Por otra parte, también se realizaron traslado de poblaciones indígenas impulsadas por intereses españoles, "300 yanacona fueron asentados en Calbuco y el resto de Abtao [...] pasaron a integrar la hueste de tropas auxiliares que disponían los españoles" (MANSILLA, 2002, p. 126)7.

\footnotetext{
${ }^{6}$ Existen tres versiones de la Ciudad de los Césares (MÁRTINIC, 2007), leyenda comenzada y esparcida por los ambientes chilotes y más australes durante el siglo XVI. Una que plantea que cuando los indígenas que estaban en Perú tomaron cuenta que los españoles iban a saquear la ciudad de Cuzco, tomaron las mayores y más valiosas cantidades de oro y partieron rumbo al sur llegando finalmente a establecerse en algún lugar desconocido de la zona sur austral de Chile. La otra versión plantea que la Ciudad de los Césares era un lugar donde habitaba gente riquísima descubierto durante una excursión practicada por Francisco César, capitán español que había integrado la expedición al Río de la Plata comandada por Sebastián Caboto. La tercera versión planteaba que algunos españoles que habían naufragado en el Estrecho de Magallanes, se fueron a las montañas y allí hicieron contacto pacífico y convivieron con indígenas. Esta última versión sería la que habría predominado por sobre las otras dos debido a que se comprobó que la expedición había tenido sobrevivientes (Ibid.).

${ }^{7}$ Es en el periodo colonial cuando Chiloé "sale al mundo", se globaliza, intensificándose el uso de rutas y prácticas productivas; resulta importante considerar relatos donde aparecen conectados las prácticas de campo y de extracción maderera: "Y nos quejamos de nuestro amo que habiendo pagado las cincuenta tablas que nos obligan pagar... (luego nos hicieron que sembrásemos) y después de sembrar nos enviaron a que (hiciésemos 2 lanchas y luego tres piraguas)...después de tres semanas nos llevan a la cordillera sin ración que cuatro cargas de (cebada podrida)... y después que fuimos a sacar otra vez 50 tablas venimos a cosechar sin ración y más dándonos a tres y a cuatro indios a que los sustentemos con nuestra comida" (Capitanía General Vol. 550. Fs. 55 y 55v, texto citado en CONTRERAS et al., 1971).
} 
En el siglo XVIII la base de la economía se situó en la explotación del Alerce. Durante toda la colonia, Calbuco fue un paso obligado para quienes se dirigían hacia Ancud, Castro, al Seno de Reloncaví y a la Cordillera en busca de la Ciudad de los Césares. El siglo XIX, es un momento importante, ya que es cuando desde Calbuco salen los veleros hacia Europa y Asia, con maderas del sur de Chile, lo cual impulso un rápido crecimiento. En este mismo período se realizaron migraciones desde la zona Calbuco/Carelmapu hacia las zonas cordilleranas (MANSILLA, 2002).

Durante el siglo XIX, los modos de vida de los habitantes de estos sectores se vieron influenciados por el fuerte auge del comercio maderero, "Ancud ocupó el título de puerto internacional...comercializando principalmente madera con California y Perú" (VIDAL, 2007, p. 63). En 1843 parte la Goleta Ancud, con pasajeros chilotes, para tomar posesión de la zona más austral de Chile, Magallanes ${ }^{8}$. También a fines del siglo XIX (1895), "pisaron suelo chilote los primeros colonos europeos... en el departamento de Ancud se formaron cuatro colonias, Huillinco, Chacao, Mechaico, y Quetalmahue" (VIDAL, 2007, p. 70-71); durante este periodo las maderas extraídas de los bosques de los sectores interiores como Huillinco, se trasladaban en balsas por el río hasta llegar a Ancud, donde llegaba a un aserradero y desde allí vía mar se trasladaban a otras regiones (VIDAL, 2007).

\section{Momento 6: Memorias e imaginarios del Siglo XX y presente en el Mar Interior de Chiloé}

Los motivos de apropiación del mar interior de Chiloé son básicamente de tipo económico (VIVALDI; ROJAS, 1992) y simbólico (DANNEMAN, 1988; BRAVO, 2004; GALLARDO, 2006). Existen intercambios y venta de productos agrícolas (BARRUEL, 1997), de pesca (CAMPOS; VARGAS, 2005), de recolección de materias primas y comercialización de productos de tradiciones alfareras (BUSTOS, 2005), venta de tejuelas y tablas (VIVALDI; ROJAS, 1992; RAMÍREZ, 1996, 1997), también existen rutas utilizadas con fines religiosos (URBINA, 2002) y turísticos (MALDONADO, 2005; BADILLA; SAN JUAN, 2005; CÁRDENAS, 2007), de intercambio local (URBINA, 2002; MONTIEL, 2003; URBINA, 2007), circuitos de rondas médicas (SANDOVAL, 1974), y transporte marítimo (SANDOVAL, 1974). Destaca también la apropiación del mar por las comunidades de pescadores artesanales (HUCKE-GAETE, 2008, 2009), principalmente, en busca de bancos naturales históricos de Erizo (INOSTROZA; ARANDA, 1988; MOLINET et al., 2008). Entre otras rutas, se utilizó para trasladar a los lugareños - previo a la construcción de la Carretera Austral - la ruta entre Puerto Montt y Puerto Chacabuco, pasando por las islas interiores (SANDOVAL, 1974); se utiliza así también la ruta desde Apiao hacia Alao, Achao, Chaulinec y Castro (BUSTOS CARA, 2005), y las rutas desde Hualaihué hacia islas cercanas y hacia las ciudades de Castro, Ancud, Calbuco y Puerto Montt (CAMPOS; VARGAS, 2005), y la ruta que conecta la isla de Chiloé con la región de Aysén (hasta Melinka y Guafo) (MOLINET et al., 2007, 2008). Otras rutas utilizadas en este periodo son: una ruta de las riberas del Golfo de Reloncaví hacia su interior (HUCKE-GAETE et al., 2008); una ruta desde Caulín hacia Manao, Chacao, Angelmó, Calbuco, Carelmapu y Quetalmahue (BUSTOS CARA, 2005); y las rutas entre islas del sector de Pichicolo y Llanchid, según se ha podido comprobar en trabajos de campos. En específico, a inicios del siglo XX, surge la primera lancha de transporte de carga y pasajeros en la localidad, la llamada 'Ángela', "pasaba caleteando...a las termas de Llancahué, la Isla Llanchid, Manzano, Hualaihué Puerto, Lleguimán, Chauchil, Rolecha...isla de Queullín y de ahí continuaba directo a Puerto Montt...la gente iba a comprar sus cosas a Puerto Montt"9. A su vez, la Velera Chilota era la principal forma mediante la cual los productos del campo y del mar salían de Chiloé continental hacia las ciudades, "llevaban... el pescado, congrio, róbalo, cholga en sacos a vender...se viajaba el Lunes y el Viernes se volvía para acá...si no quedábamos en Rolecha por los vientos del sur, si no en la misma lancha" (Ibid. $)^{10}$.

\footnotetext{
${ }^{8}$ Respecto a este punto, existe un buen seguimiento de esos procesos migratorios hacia Patagonia chilena y argentina por parte de chilotes a fines del siglo XIX e inicios del XX en LAUSIC, 2005, MANCILLA; REHBEIN, 2009.

${ }^{9}$ Entrevista a Juan Carlos Burnes (CAMPOS; VARGAS, 2005).

${ }^{10}$ Los isleños viajan en botes particulares, los que debían salír a las tres de la madrugada, llegando a Castro a las nueve de la mañana, a las siete de la tarde zarpaban desde Dalcahue llegando a su isla a media noche. Otro caso paradigmático es la lancha hospital "Dra. Juricic" que realiza rondas por las veintitrés islas del departamento de Quinchao, avisando su parada sólo en cinco de ellas: Quenac, Chaulinec, Buta-Chauques, Voigue y Chulín. La asistencia escolar se ve reducida en días de temporal, para aquellos niños que deben trasladarse en botes a sus recintos. El aislamiento propició el desarrollo de "economías cerradas", familias distendidas en rumbos migratorios anuales del hombre y prácticas agrícolas femeninas (SANDOVAL, 1974). Los lugareños debían llegar hasta la Isla Llanchid a través de bongos (tronco cavado) o lanchas veleras, para dar santa sepultura a sus seres queridos, situación que se complicaba con las adversas condiciones climáticas principalmente en la época de invierno.
} 
En este periodo resalta una práctica pesquera particular realizada en la zona contigua (X y XI región). Para las pesquerías de "Erizo, Lugas y Jaibas se desarrollan...lejos de los puertos de desembarque, intervienen embarcaciones extractivas (con buzos) y transportadoras que acopian y luego trasladan el recurso hacia puertos de desembarque autorizados" (MOLINET et al., 2007, p. 165). La práctica implica un sistema pesquero móvil que puede trasladarse al lugar donde el saber del pescador artesanal (buzos) ha identificado bancos históricos. En efecto, la flota viaja desde Dalcahue, Quellón y Melinka a los diferentes caladeros y las transportadoras realizan series de viajes hacia los puertos de "Dalcahue, Queilen, Curanue, Auchac y Quellón en la X Región y Melinka y Quellón en la XI Región. El puerto de Quellón...presenta desembarques provenientes de ambas regiones" (Ibid., p. 167).

\section{Exoducción: la construcción social del tiempo en el mar interior de Chiloé}

El maritorio chilote es un mar vivo que no deja olvidar a sus usuarios dónde ir y dónde volver; verdaderamente. En conjunto, en los 6 momentos descritos se señalan y rescatan las experiencias de pescadores y otros usuarios en momentos del viaje como apropiaciones socioculturales del mar interior. Las rutas y trayectorias unidas por las labores artesanales a escala humana delatan una construcción cultural repleta de imágenes y redes. La temporalidad del viaje marítimo considera de esta manera las embarcaciones, asociadas al clima, a los tiempos de espera y de detención, a los tiempos para estar en los centros urbanos, y a los tiempos comunitarios, a los tiempos para buscar las maderas e insumos. En todo esto, las motivaciones y afectos acumulados por los años surgen con fuerza, así como la mirada retrospectiva respecto de los cambios en las prácticas de viaje, en tanto costumbres pasadas, presentes, y también proyecciones futuras. En todo esto se interrelacionan aspectos etnográficos, de rutas y trayectorias asociadas a procesos económicos, como producción, distribución, intercambio y consumo en el Mar Interior de Chiloé. El maritorio chilote al ser así un espacio apropiado y valorizado
(SAUER, 1994) por los actores y usuarios, resulta ser una entidad multiescalar en la cual se representan y reproducen dinámicas espacio-temporales (McDOWELL, 1994).

De acuerdo a la literatura sistematizada en los 6 momentos señalados se expresa la pluralidad de usos y tipos de rutas existentes en el mar interior, un elemento importante de subrayar es que la utilización intensiva de algunas rutas no ha significado la desaparición de otras. Aún cuando la tecnologización de la pesca ha provocado profundas brechas entre los medianos y los pequeños pescadores, siendo los últimos quienes han mantenido en funcionamiento las rutas más periféricas o imposibles de abordar por embarcaciones mayores, se mantiene pragmáticamente la necesidad de utilizar lo que ha sido previamente marcado en las memorias litorales. Lo cual otorga los fundamentos para identificar que las configuraciones del tiempo en el Mar Interior de Chiloé se comportan al menos de dos maneras posibles: a) como un conjunto de relaciones (de simultaneidad, de sucesión - antes y después -, de interposición - entre -, topológicas - finitud e infinitud); b) como métricas (series cronométricas). En su conjunto estas configuraciones del tiempo develan distintos imaginarios sobre el mar interior de Chiloé, y proyectan el maritorio hacia el futuro. Conviene subrayar, sin embargo, que sí bien es cierto el tiempo -la memoria, los ciclos, las rutinas, la orientación temporal de los actores- se ancla en el espacio y en las memorias litorales, no se agota en ellos. De la misma manera, el maritorio chilote permanece - aún y cuando modificado - para varias generaciones: lo cual permite en definitiva que un pescador, por ejemplo, imagine a sus antepasados ocupando el mismo espacio que él habita actualmente (aunque ya no estén ahí), y a sus descendientes apropiándose del mismo (aunque todavía no estén aquí) (CUNHA, 1987). Siguiendo a Castoriadis podemos decir entonces que las apropiaciones socioculturales del mar interior de Chiloé se dan en el tiempo - y en el tiempo se hacen -, siendo el pasado algo más que una simple repetición (CASTORIADIS, 1984). Las apropiaciones socioculturales hacen alusión así a las emergencias del tiempo en tanto categoría de la transformación y cambio en el maritorio chilote, lo cual en última instancia - y en concordancia con VIEIRA y WEBER (1997) - proporciona un nuevo imaginario para el maritorio chilote: mirar el pasado con ojos modernos. 


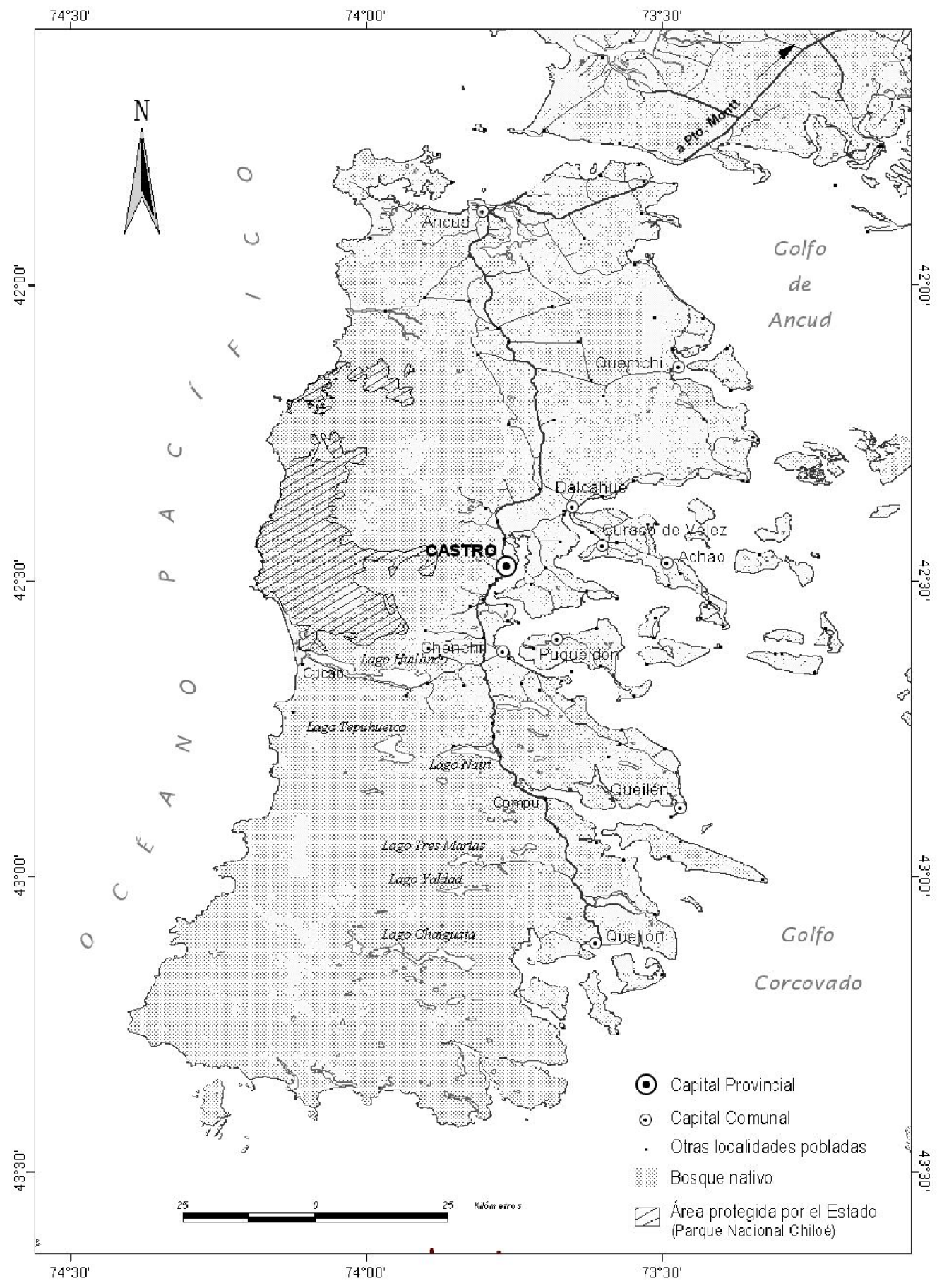

MAPA DEL MAR INTERIOR DE CHILOÉ. 


\section{Bibliografía}

ALBORNOZ, A. M.; HAJDUK, A. Antecedentes arqueológicos e históricos del camino de las lagunas. Tiempos Patagónicos, Buenos Aires: Facultad de Derecho y Ciencias Políticas, Universidad Católica Argentina, v. 7, p. 24-29, 2001.

; MONTERO, G. Nahuel-Huapi: Antropología e historia regional de un área de frontera. En: JORNADAS DE HISTORIA DE LA PATAGONIA, 3. Antropología e Historia: interdisciplinariedad, convergencias disciplinares y estudios de caso en Patagonia. Anales. San Carlos de Bariloche, 2008.

ÁLVAREZ, R. Reflexiones en torno a las identidades de las poblaciones canoeras situadas entre los 44 y 48 de latitud sur, denominadas chonos. Anales del Instituto de la Patagonia, v. 30, p. 79-86, 2002. Serie Ciencias Humanas.

. Conchales arqueológicos y comunidades locales de Chiloé a través de una experiencia arqueológica de educación patrimonial. Chungará, Revista de Antropología chilena, volumen especial, n. 36, p. 1151-1157, 2004.

; GODOY, M. Experiencias rurales de educación patrimonial en la Décima Región. Comunidades mapuche-huilliche de Huiro, Astilleros y Rauco. Revista Austral de Ciencias Sociales, n. 5, p. 29-38, 2001.

; MUNITA, D.; FREDES, J.; MERA, R. Corrales de pesca en Chiloé. Concurso regular de proyectos del fondo nacional de la cultura y las artes, 2008.

ANUCH, D. La escala de los asentamientos del siglo XXI en Chiloé. Memoria de investigación Arquitectura. Universidad Arcis Patagonia, 2008.

ARIZPE, L. Los debates internacionales en torno al Patrimonio Cultural Inmaterial. Cuicuilco, Escuela Nacional de Antropología e Historia. Distrito Federal de México, v. 13, n. 38, p. 13-27, septiembre-diciembre 2006.

ASPILLAGA, E.; CASTRO, M.; RODRIGUEZ, M.; OCAMPO, C. Paleopatología y estilo de vida: el ejemplo de los Chono. Revista Magallania, v. 34, p. 77-85, 2006.

BADILLA, M.; SAN JUAN, C. Los impactos culturales del agroturismo en las familias campesinas chilotas. Tesis para optar a título de profesor en Historia, Geografía y Ed. Cívica. Universidad de la Frontera. Temuco, 2005.

BARROS ARANA, D. Historia general de Chile. Santiago, 2. ed. Editorial Universitaria y Centro de Investigaciones Diego Barros Arana, 2000.
BARRUEL, E. Los fiscales de Chiloé: Una ruta devocional, Ediciones Orígenes, 1997.

BELLELLI, C.; SCHEINSOHN, V.; PODESTÁ, M. Arqueología de pasos cordilleranos: un caso de estudio en Patagonia norte durante el holoceno tardío. Boletin del Museo Chileno de Arte Precolombino, v. 13, n. 2, p. 37-55, 2008.

BENGOA, J. Historia del Pueblo Mapuche. Siglos XIX y XX. Santiago: Editorial LOM, 2000.

BRAICOVICH, R.; CARACOTCHE, S. Una biografía de las canoas monóxilas de la región andina norpatagónica. Perspectivas para su memoria y conservación. En: JORNADAS DE HISTORIA DE LA PATAGONIA, 2. Anales. San Carlos de Bariloche, 2008.

BRAVO, J. La cultura chilota y su expresión territorial en el contexto de la globalización de la economía. Memoria para optar al título profesional de geógrafo. Universidad de Chile, 2004.

BUSTOS CARA, R. Patrimonialización de valores territorial, turismo, sistemas productivos y desarrollo local. Aportes y Transferencias, v. 8, n. 2, p. 11-24, 2004.

. Reconstrucción de las tradiciones alfareras de Caulín y Apiao a partir de fuentes orales, Chiloé (Décima Región). Licenciado en Antropología. Universidad Austral de Chile, 2005.

CAMPOS, M.; VARGAS, G. Hornopirén después de un siglo.1900-2000. Una propuesta didáctica para abordar la historia local en la educación media. Tesis para optar al título de profesor de historia, geografía y ed. Cívica y al grado académico de licenciado en educación. Universidad de la Frontera. Temuco, 2005.

CÁRDENAS, C. Propuesta de desarrollo turístico sostenible en base al turismo cultural y de naturaleza para la ciudad de Achao, Comuna de Quinchao, provincia de Chiloé. Tesis para optar al grado de licenciado en educación y al título de profesor en Historia, Geografía y Educación Cívica. Universidad de la Frontera. Temuco, 2007.

CÁRDENAS, R.; MONTIEL, D.; HALL, C. Los Chono y los veliche de Chiloé. Santiago: Ediciones Olimpo, 1993.

CASTORIADIS, C. Tiempo e imaginación. Zona Erógena, n. 18, p 1- 17, 1984. Disponible en: <http://es.scribd.com/ doc/38702250/Castoriadis-Tiempo-e-Imaginacion>. Acceso en Noviembre 2008. 
CHAPANOFF, M. Hallazgo de una canoa monóxila en la playa de Chaicura: evidencias de navegación en ambientes marítimos en el archipiélago de Chiloé. En: CONGRESO NACIONAL DE ARQUEOLOGÍA CHILENA, 28. Simposio arqueología marítima; Nuevos avances de la investigación en Chile y el contexto Latinoamericano. Anales. Museo Historia Natural. Valparaíso. Chile, 2009.

CONTRERAS, J.; FLORES, E.; HERRERA, I.; MAZZEI, L.; RIVERA, A.; ROMERO, R. La población y la economía de Chiloé durante la colonia (1567-1826). Concepción, Chile: Ediciones Universidad de Concepción, 1971.

CUNHA, L. Entre o mar e a terra - tempo e espaço em Barra da Lagoa - SC - Brasil. Tesis (Mestre em Ciências Sociais) Programa de Estudos de Pós-Graduação em Ciências Sociais da Pontifícia Universidade Católica de São Paulo, 1987.

DANNEMANN, M. La actitud mítica en Chiloé y su influjo en la XI región. En: ACUÑA, Vázquez de et al. Chiloé y su influjo en la XI Región. Santiago, 1988. p. 75-80. Colección Terra Nostra.

DE CÓRDOVA, P. Historia de Chile (1492-1717). En colección de historiadores de Chile y documentos relativos a la historia nacional. Santiago de Chile, 1862.

DILLEHAY, T. Comentario al simposio ocupaciones iniciales de cazadores recolectores en el sur de Chile. Chungará, Revista de Antropología Chilena, volumen especial, p. 277-281, 2004.

EMPERAIRE, J. Los nómades del mar. Versión española. Santiago de Chile: Ediciones de la Universidad de Chile, 1963.

FERRER, H. Las expediciones hidrográficas y su importancia para las comunicaciones marítimas. En: ACUÑA, Vázquez de et al. Chiloé y su influjo en la XI Región. Santiago, 1988. p. 12. Colección Terra Nostra.

FLORES, C. Estrategias de aprovechamiento de la diversidad ecológica del intermareal prehistórico conchales del seno de Reloncaví, X Región, Chile. En: MORELLO, F.; MARTINIC, M.; PRIETO, A.; BAHAMONDE, G. (Eds.). Arqueología de Fuego-Patagonia. Levantando piedras, desenterrando huesos ... y develando arcanos. Punta Arenas: Ediciones CEQUA, 2007. p. 33-38.

GAETE, N.; NAVARRO, X. Estrategias de vida de canoeros cazadores pescadores recolectores del seno de Reloncaví. Entre el bosque siempreverde y el mar interior. Región de Los Lagos, Chile. En: CIVALERO, M. T.; FERNÁNDEZ, P. M.; GURÁIEB, A. G. (Comps.). Contra viento y marea. Arqueología de Patagonia, Buenos Aires: inapl y Sociedad Argentina de Antropología, p. 217-235, 2004.
; CONSTANTINESCU, F.; MERA, C.; SELLES, D.; SOLARI, M-E.; VARGAS, M-L.; OLIVA, D.; DURAN, L. Una mirada al modo de vida canoero del mar interior desde Piedra Azul. Chungara, Revista de antropología Chilena, Volumen Especial, p. 333-346, 2004.

GALLARDO, C. Curaco de Vélez, Chiloé, Baluarte del orgullo y la fé. Tesis para optar al título de Profesor de Historia, Geografía y Ed. Cívica y al Grado de Licenciado en Educación. Temuco: Universidad de la Frontera, 2006.

GARCÍA, J. Anuario Hidrográfico de la Marina de Chile, año $X I V$. Santiago: Imprenta Nacional, 1889.

HANISCH, W. Isla de Chiloé: Capitanía de rutas australes. Santiago de Chile: Academia Superior de Ciencias Pedagógicas de Santiago, 1982.

HAU, V. Puerto de pasajeros y centro de acción social para las comunidades de mar interior. Memoria proyecto de Titulo. Escuela de Arquitectura. Universidad de Chile, 2006.

HOCART, A. Mito, ritual y costumbre. Ensayos heterodoxos. Madrid: Siglo XXI, 1975.

HUCKE-GAETE, R.; ALVAREZ, R.; RUIZ, J.; TORRES, J. P. Investigación para el desarrollo del área marina costera protegida de Chiloé. Primer Informe de avance. Proyecto BIP No 30040215-0. Universidad Austral de Chile, 2008.

; $\quad ; \quad$; $\quad$. Investigación para el de sarrollo del área marina costera protegida de Chiloé. Segundo Informe de avance. Proyecto BIP N ${ }^{\circ}$ 30040215-0. Universidad Austral de Chile, 2009.

INOSTROZA, F.; ARANDA, E. Situación y perspectivas del sector pesquero en las regiones X y XI. En: ACUÑA, Vázquez de et al. Chiloé y su influjo en la XI Región. Santiago, 1988. p. 163-183. Colección Terra Nostra.

LAUSIC, S. Migraciones del archipiélago de la isla grande de Chiloé hacia la Patagonia (Chile-Argentina) y participación en el sindicalismo obrero. Archivo Chile. CEME, 2005.

LEGOUPIL, D. Recolectores de moluscos Tempranos en el sureste de la isla de Chiloé: una primera mirada. Revista Magallania, v. 33, p. 51-61, 2005.

; FONTUGNE, M. El Poblamiento Marítimo en los Archipiélagos de Patagonia: Núcleos Antiguos y Dispersión Reciente. Ans. Inst. Patag. Ser. Cs. Hnas., v. 25, p. 75-87, 1997. LEÓN, M. Cultura de la muerte en Chiloé. Santiago: RIL Editores, 2007.

LIRA, N. Canoas monóxilas en el Centro-Sur de Chile. Navegando sobre los árboles. Tesis para optar al titulo de Arqueó- 
logo, Santiago, Chile, Universidad de Chile (UCH), Facultad de Ciencias Sociales, Departamento de Antropología, 2007.

MALDONADO, I. Turismo rural y desarrollo en la Comuna de Calbuco, X Región de Los Lagos. Una propuesta educativa en geografía local. Tesis para optar al título de Profesor de Historia, Geografía y Educación Cívica. Temuco: Universidad de la Frontera, 2005.

MANCILLA, C.; REHBEIN, R. Comunicación y representación en migraciones. Sobre la producción e institucionalización del imaginario de la vida errante en los procesos de transmisión cultural: El caso de Chiloé en la primera mitad del siglo XX. Revista Faro Monográfico, año 5, n. 9, 2009. Disponible en: $<$ http://web.upla.cl/revistafaro/n09/pdf/art04.pdf $>$. Acceso en Janeiro 2010.

MANSILLA, J. Exploraciones hidrográficas inglesas en los archipiélagos de Chiloé y los Chono (1829-1835) El viaje de Charles Darwin. Revista cultura de y desde Chiloé. Castro, 1991.

Avistamiento de Calbuco por los españoles en el siglo XVI. Boletín Literario Araña Gris, Calbuco, n. 21, p. 10-14, 1992.

. La población de Calbuco: evolución en cifras, siglos XVII-XX. Revista Austral de Ciencias Sociales, n. 6, p. p. 125-134, 2002.

. Los alerceros calbucanos del siglo XIX. En: Pontificia Universidad Católica de Chile, Historias y leyendas de mi pueblo. Vicerrectoría de Comunicaciones y Extensión-PUC, Chile y Asociación AFP. Santiago, 2004.

La isla Lagartija y su presencia en la historia calbucana. Informe para la Oficina de Obras. Municipalidad de Calbuco, 2005.

Ercilla, La Araucana y Calbuco. Cuadernos del Caicaen. Historia y Folklore desde las Islas. Calbuco, 2008.

McDOWELL, L. The transformation of cultural geography. En: GREGORY, D.; MARTIN, R.; SMITH, G. (eds.): Human Geography, Ed. Macmillan Press Ltda., 1994.

MARINO, M. Chiloé: economía, sociedad, colonización. Ancud: Ediciones Victor Naguil, 1985.

; BIANCHI, S. Chiloé: cultura de la madera. Santiago, Chile, 1980.

; OSORIO, C. Chiloé cultura de la madera. Proceso a los brujos. Sin datos de edición, 1983.

MARTINIC, M. De la Trapanada al Aysen. Santiago: Pehuén Editores, 2005.
De los césares de la Patagonia. Magallania, v. 32, p. 7-14, 2007.

MEMORIAS DEL IV Encuentro-Taller Latinoamericano de Teología India (2004) En busca de la tierra sin mal. Ediciones ABYA-YALA, Quito.

MENA, F. Presencia indígena en el litoral de Aisén. Trapananda, año VIII, n. 5, p. 203-213, 1985.

MOLINET, C.; ARÉVALO, A.; DÍAZ, M.; DÍAZ, P. Uso del borde costero en el mar interior de la Región de Aysén y de Los Lagos: escalas e interacción de los procesos de pesca y acuicultura. En: LOVATELLI, A.; FARÍAS, A.; URIARTE, I. (Eds.). Estado actual del cultivo y manejo de moluscos bivalvos y su proyección futura: factores que afectan su sustentabilidad en América Latina. Taller Técnico Regional de la FAO. 20-24 de agosto de 2007, Puerto Montt, Chile. FAO Actas de Pesca y Acuicultura, Roma: FAO, n. 12, p. 237-247, 2008.

; BARAHONA, N.; MATAMALA, M. Diagnóstico biológico pesquero para recursos bentónicos de la zona contigua, Xy XI Región. Informe Final. Proyecto FIP n. 200551. Universidad Austral de Chile, Pupelde e IFOP. Fondo de Investigación Pesquera, 2007.

MONTIEL, D. Chiloé: Crónicas de un mundo insular. Puerto Montt: Dimar Ediciones, 2003.

MORENO, R. El modelo pastoral jesuítico en Chiloé colonial. Revista Veritas, v. 1, n. 14, p. 183-203, 2006.

MÜLLER, M. Jesuitas centro-europeus o "alemanes" en las misiones de indígenas en las antiguas provincias de Chile y del Paraguay. En: Zulmira Santos, São Francisco Xavier: nos 500 anos do nascimento de São Francisco Xavier: da Europa para o mundo 1506-2006. p. 87-102. Porto: Centro Interuniversitário de História da Espiritualidade, 2007.

NEGRÓN, J. Los franciscanos de Chiloé, misioneros en la Araucanía. Revista Cultura de y desde Chiloé, n. 10, p. 2132,1980 .

OCAMPO, C.; RIVAS, P. Poblamiento temprano de los extremos geográficos de los canales patagónicos: Chiloé e isla Navarino 1. Revista Chungará (Arica), v. 36, supl. espec. Arica, 2004.

ORQUERA, L. A.; PIANA, P. Arqueología de la Región del Beagle (Tierra del Fuego, República Argentina). Publicaciones de la SAA, 1999.

PORTER, C. Pleistocene glaciation in the southern Lake District of Chile. Quaternary Research, v. 16, p. 263-292, 1981. 
Gua-010, un sitio costero erosionado en una zona sísmica activa. Actas del XII Congreso Nacional de Arqueología Chilena. Boletín, 4, T1, Museo Regional de Araucanía, Temuco, p. 81-94, 1992.

RAMÍREZ, F. Ecohistoria y destrucción en Chiloé continental: El valle del Vodudahue 1700-1996. Actas VII Jornadas de Historia Regional de Chile. Universidad de Chile, Santiago. Julio 1996, 1997.

La necesidad de avanzar hacia una historia ecológica para Chile. Revista Ambiente y Desarrollo, v. 12, n. 2, p. 6168, 1996.

RIVAS, P.; OCAMPO, C.; ASPILlAGA, E. Poblamiento Temprano de los Canales Patagónicos: El Núcleo Ecotonal Septentrional. Anales Instituto de la Patagonia. Serie Cs. Hs., v. 27, p. 221-230, 1999.

RODRÍGUEZ, M. Rumbo al sur: la histórica expedición de la goleta Ancud. Archivo Chile, 2004.

Rumbo al sur: la histórica expedición de la goleta Ancud al Estrecho de Magallanes, 1843. Coyuntura Política. Disponible en: <http://coyunturapolitica.wordpress.com/2008/09/20/ rumbo-al-sur-la-historica-expedicion-de-la-goleta-ancud-alestrecho-de-magallanes-en-1843/>. Acesado en: 2008.

SANDOVAL, H. El Villorrio: un factor de desarrollo en el archipiélago interior de Chiloé. Departamento de Urbanismo y Vivienda. Universidad Católica de Chile, 1974.

SANDOVAL, L. Arquitectura religiosa de Chiloé. Universidad Arcis. Patagonia. Sede Castro. Chiloé, 2007.

SANTANA, R. Articulación entre cultura de la madera y explotación durable del bosque nativo en Chiloé. Revista Líder, n. 9, p. 1-21, 2001.

.Émergence de stratégies patrimoniales dans l'archipel de Chiloe (Chili). Les enjeux autour de l'architecture en bois. Géocarrefour, v. 79, n. 3, p. 257-264, 2004.

SAUER, C. La Geografía Cultural. En: Gómez Mendoza, J. y otros. El pensamiento geográfico. Madrid: Alianza Editorial, S.A., 1994.

SMITH, R. Datos estadísticos sobre el comercio de importación en el Perú en los años de 1698 y 1699. Revista Chilena de Historia y Geografia, v. 113, p. 162-177, 1949.

SUBERCASEAUX, B. Chile o una loca geografia. Santiago: Editorial Ercilla, 1940.

THAYER, T. Observaciones acerca del viaje de don García Hurtado de Mendoza a las Provincias de los Coronados y
Ancud. Revista Chilena de Historia y Geografia, Santiago, Tomo 7, p. 323-381, 1913.

THER, F. Complejidad territorial y sustentabilidad: notas para una epistemología de los estudios territoriales. Revista Horizontes Antropológicos, año 12, n. 25, p. 105 - 115, jan./ jun. 2006.

TORREJÓN, F.; CISTERNAS, M.; ARANEDA, A. Efectos ambientales de la colonización española desde el río Maullín al archipiélago de Chiloé. Revista Chilena de Historia Natural, n. 77, p. 661-677, 2004.

TRIVERO, A. Los primeros pobladores de Chiloé. Génesis del Horizonte Mapuche. Ñuke Mapuforlaget, 2005.

URBINA, M. La puerta de Nahuelhuapi: imaginario y formas de exploración del territorio en la frontera austral del reino de Chile. Actas del XII Congreso de la Asociación Española de Americanistas, v. I. Universidad de Huelva, p. 347-367, 2007.

URBINA, R. Del período indiano a la cultura chilota. Revista Cultura de y desde Chiloé, p. 35-43, 1986.

. Chiloé, foco de migraciones. En: ACUÑA, Vázquez

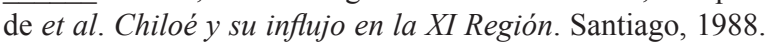
p. 31-53. Colección Terra Nostra.

. Las misiones franciscanas de Chiloé a fines del siglo XVIII. Santiago: Elástole, 1990.

. La vida en Chiloé en los tiempos del fogón. 19001940. Valparaíso: Universidad de Playa Ancha Editorial, 2002.

El Pueblo chono: de vagabundo y pagano alzado a cristiano y sedentario amestizado. En: NAVARRO, Fernando (Coord.). Orvis Incognitvs: avisos y legajos del nuevo mundo: homenaje al profesor Luis Navarro García, v. 1, p. 325-346, 2007.

URBINA, Rodolfo. Los Chonos en Chiloé: Itinerario y aculturación. Revista Chiloé, n. 9, p. 29-42, 1988.

VÁSQUEZ, I.; DEL POSTIGO, García. Chiloé y su devenir. En: ACUÑA, Vázquez de et al. Chiloé y su influjo en la XI Región. Santiago, 1988. II Jornadas Territoriales. Colección Terra Nostra, n. 12.

VIDAL, V. Una aproximación a la colonización europea en la comuna de Ancud. Provincia de Chiloé, entre los años 1890-1897. Tesis para optar al título de Profesor de Estado en Historia, Geografía y Educación Cívica, y al grado de Licenciado en Educación. Temuco: Universidad de la Frontera. Temuco, 2007. 
THER, Francisco. Configuraciones del tiempo en el Mar Interior de Chiloé y su relación...

VIDAL GORMAZ, F. Ercilla y el descubrimiento de Chiloé. Revista de Santiago, Santiago de Chile, n. 1, 1872.

VIEIRA, P. F.; WEBER, J. Introdução geral: sociedades, naturezas e desenvolvimento viável. In: (Orgs.).

Gestão de recursos naturais renováveis e desenvolvimento.
Novos desafios para a pesquisa ambiental, São Paulo: Cortez, p. 17-49, 1997.

VIVALDI, R.; ROJAS, E. La madera, material de una cultura. En: Gómez, C., Montiel, D., ed., Chiloé a 500 años. Texto consultivo para la educación media. Gobernación Provincial de Chiloé, 1992.

Recebido em março de 2011.

Aceito em abril de 2011.

Publicado em junho de 2011. 